\title{
RESPUESTAS KANTIANAS PARA LOS PROBLEMAS DE LA TÉCNICA MODERNA EN EL PRINCIPIO DE RESPONSABILIDAD DE JONAS
}

\author{
Laurentzi de Sasia Rubio ${ }^{1}$ \\ Pontificia Universidad Católica de Chile
}

\begin{abstract}
Resumen: El siguiente trabajo es una respuesta a la aseveración de Jonas de que las teorías éticas previas son incapaces de proveer respuestas a los nuevos problemas que presenta la técnica moderna. Específicamente, que el imperativo categórico de Kant es incapaz de proveer respuestas para novedosos problemas importantes como lo son la justificación moral para la existencia de la humanidad y el mundo. Este trabajo provee: 1) una demostración sobre cómo la interpretación del imperativo categórico de Jonas es incompleta lo que hace que su aseveración inicial sea errónea y 2) las respuestas kantianas prácticas a los problemas de la técnica moderna que Jonas presenta, proveyendo las justificaciones teóricas necesarias basadas en la Crítica de la Razón pura y La Fundamentación de la Metafísica de las Costumbres
\end{abstract}

Descriptores: Kant · Jonas · Imperativo categórico · Ética · Técnica moderna · Existencia de la humanidad - Fundamentación de la metafísica de las costumbres · Principio de responsabilidad $\cdot$ Poder querer

Abstract: The following work is a response to Jonas' claim that previous ethical theories are incapable to provide answers to the new problems that modern techniques present. Specifically, how Kant's categorical imperative cannot provide answers to new important problems like the moral justification for the existence of humanity and the world. This work provides 1) a demonstration on how Jonas' interpretation of the categorical imperative is incomplete and therefore his initial claim is wrong and 2) practical Kantian answers to Jonas' modern technique problems with the necessary theoretical justification based on Kant's Critique of Pure Reason and Groundwork of the Metaphysics of Morals.

Keywords: Kant $\cdot$ Jonas $\cdot$ Categorical Imperative $\cdot$ Ethics $\cdot$ Modern Technique $\cdot$ Existence of humanity Groundwork of the metaphysics of morals · Imperative of responsibility · Will

Enviado: 05/11/2018. Aceptado: 26/12/2018

\section{INTRODUCCIÓN}

El propósito de este trabajo es proveer una respuesta kantiana a dos problemas fundamentales de interpretación que hace Jonas en su obra El principio de responsabilidad, sobre cómo dicha ética está imposibilitada para lidiar con las nuevas problemáticas que provee la técnica moderna. El primer problema de

\footnotetext{
${ }^{1}$ Programa de Licenciatura en Filosofía. E-mail: laurentzidesasia@gmail.com
} 
interpretación es que Jonas analiza el imperativo categórico kantiano de manera parcial, pues sólo hace énfasis en su uso estrictamente lógico y no en un sentido más volitivo, que es complementario. Esto le permite a Jonas aseverar que el imperativo categórico es incapaz de lidiar con problemáticas morales que vayan más allá de la contradicción lógica entre conceptos (e.g., si la humanidad debe o no existir), con lo cual asegura que la ética que él propone es absolutamente novedosa y necesaria, pues sí puede lidiar con ese tipo de problemas. El segundo problema (que se deriva del primero) es que Jonas asevera que todas las éticas clásicas -entre ellas la kantianafuncionan teniendo en cuenta como base tácita verdadera tres premisas previamente pensadas como fijas, pero las cuales hoy en día son potencialmente alterables por la técnica moderna, haciendo que las éticas tradicionales sean incapaces de debatir los nuevos problemas éticos.

Para responder a estas supuestas imposibilidades que plantea Jonas, el ensayo expone primero la postura que Jonas provee en el Principio de responsabilidad sobre la ética kantiana, explicando: A) El problema del alcance moral y práctico del imperativo categórico y cómo éste no permite resolver problemas tales como la existencia de la humanidad en la tierra. B) El problema de las tres premisas tácitas que ya no se cumplen necesariamente y que imposibilitan que la ética kantiana ofrezca una respuesta ante las nuevas problemáticas propias de la técnica moderna. Segundo, se provee una reinterpretación del imperativo categórico tomando como base el texto Fundamentación de una metafisica para las costumbres para mostrar que su uso no es meramente lógico y que, por lo tanto, sí permite tratar problemas como la existencia de la humanidad. Por último, el artículo busca mostrar cómo la ética kantiana sí es capaz de proponer respuestas ante las nuevas interrogantes éticas propias de la técnica moderna, aunque las tres premisas tácitas que antes eran fijas ahora sean (o lleguen a ser) variables.

\section{LA ÉTICA DE JONAS COMO UNA ÉTICA CON UN ALCANCE SIN PRECEDENTE Y SU} INTERPRETACIÓN SOBRE LA ÉTICA KANTIANA Y EL IMPERATIVO CATEGÓRICO.

En su obra El principio de responsabilidad el filósofo Hans Jonas hace una crítica de los modelos éticos que lo preceden pues para él estos son insuficientes para tratar con las nuevas acciones humanas que la nueva técnica moderna posibilita. Las acciones humanas del pasado eran limitadas y no tenían la capacidad de afectar permanentemente el mundo o a la propia naturaleza humana. En el siglo XX, sin embargo, el ser humano obtiene acceso a nuevas acciones provistas por las nuevas técnicas modernas que aumentan el impacto espaciotemporal que éste puede llegar a tener, tanto en sí mismo como en todo lo que lo rodea y potencialmente lo rodeará. 
Todas las éticas anteriores, menciona Jonas, compartían tres premisas de manera tácita: 1) Una condición humana fija y para siempre; 2) Sobre la base de la condición humana fija se puede determinar con claridad el bien humano; y, 3) El alcance de la acción humana -y con ella su responsabilidad- está delimitado (Jonas, 1995, p. 23). Estas premisas, sin embargo, ya no son necesariamente válidas porque: (1) con la técnica moderna la condición humana ${ }^{2}$ deja de estar fija necesariamente; por lo cual, (2) su bien tampoco queda determinado con claridad; y porque (3) el alcance espaciotemporal de la acción humana deja de estar delimitado, con lo cual su responsabilidad aumenta. Como ejemplo se puede analizar grosso modo el caso de que el ser humano sea potencialmente capaz de alterar genéticamente su cuerpo usando la técnica moderna, quizás haciéndolo capaz de vivir indefinidamente, afectando así un aspecto fundamental de su condición humana.

El ser humano, Jonas concluye, puede llevar a cabo acciones con un alcance espaciotemporal de tal magnitud que pueden llegar a afectar no sólo a los seres humanos más cercanos, sino que también pueden afectar al mundo mismo, a todos quienes lo habitan y a las generaciones que todavía están por venir. Este nuevo alcance del actuar posibilitado por la técnica moderna exige una nueva ética que sea capaz de hacerse cargo de las acciones posibles en este nuevo escenario: "la naturaleza cualitativamente novedosa de varias de nuestras acciones ha abierto una dimensión totalmente nueva de relevancia ética y no prevista en las perspectivas y cánones de la ética tradicional" (Jonas, 1995, p. 23). Jonas afirma que las éticas tradicionales son incapaces de prever y guiar el nuevo actuar humano porque hay un cambio cualitativo en nuestra forma de actuar gracias a la técnica moderna.

En El principio de responsabilidad Jonas no hace un análisis exhaustivo para demostrar cómo lo que él llama ética tradicional es incapaz de dar cuenta del nuevo actuar humano. Más bien se satisface con asumir que el limitado impacto que tuvo el actuar humano a lo largo de historia nunca lo obligó a pensar sobre consecuencias potenciales como las que se nos presentan hoy, y que, por lo tanto, los sistemas éticos tradicionales no se hacen cargo de estas nuevas acciones y tampoco tenían por qué hacerlo. La ética como disciplina práctica versa sobre la acción y es razonable que entregue directrices sobre lo que de hecho se puede hacer -o tal vez incluso algunos casos hipotéticos que no parecen imposibles-, pero el actuar posible gracias a la técnica moderna presenta un salto cualitativo, toda una nueva problemática para las cuales las éticas tradicionales no sirven.

Jonas, sin embargo, sí menciona y analiza el imperativo categórico ${ }^{3}$ kantiano como un ejemplo de cómo una ética tradicional es incapaz de hacerse cargo

\footnotetext{
${ }^{2} \mathrm{O}$ al menos rasgos fundamentales de la condición humana.

${ }^{3}$ En su versión "Obra de tal modo que puedas querer también que tu máxima se convierta en ley universal” (Jonas, 1995, p. 39)
} 
de las consecuencias de las nuevas acciones posibles gracias a la técnica moderna. Específicamente, Jonas plantea el problema que tiene el imperativo categórico para asegurar la existencia de la humanidad. Dado que la técnica moderna permite efectivamente llevar acciones que pueden terminar con la humanidad, si esto es algo moralmente malo, entonces el imperativo categórico debería ser capaz de prohibirlo. Sin embargo, Jonas argumenta que éste es incapaz de asegurar la existencia de la humanidad porque, según su interpretación, sólo funciona prohibiendo acciones que provoquen una contradicción lógica entre la razón y la concordancia consigo misma. Dicho en términos kantianos, el imperativo categórico sólo se puede aplicar como una regla que determina la inmoralidad de una acción cuando hay una contradicción entre un concepto singular y su forma universal y, por lo tanto, sólo hay una prohibición moral cuando una máxima (por definición una norma del actuar personal $)^{4}$ no se puede hacer universal porque se contradice.

En el caso de la existencia de la humanidad, no hay ninguna autocontradicción lógica en el caso de que ésta deje de existir. Citando a Jonas (1995): "no hay autocontradicción en la idea de que la humanidad deje un día de existir (...)", a lo cual además añade que "tampoco lo hay, por consiguiente, en la idea de que la felicidad de las generaciones presentes y próximas se obtenga a costa de la infelicidad o incluso la inexistencia de generaciones posteriores" (p. 39). El imperativo categórico kantiano sería incapaz de tratar el tema pues ya presupone la existencia de una sociedad de humanos. "Presupuesta la existencia de una sociedad de actores humanos (seres racionales actuantes), la acción tiene que ser tal que pueda ser pensada sin autocontradicción como práctica universal de esa comunidad." (Jonas, 1995, p. 39).

Este problema del imperativo categórico kantiano permite a Jonas postular su imperativo como novedoso, uno que sí se adecúa al nuevo tipo de acciones humanas y a sus consecuencias: "Obra de tal modo que los efectos de tu acción sean compatibles con la permanencia de una vida humana auténtica en la Tierra" (Jonas, 1995, p. 40). Con esto Jonas asegura una concordancia de los efectos últimos con la continuidad de la actividad humana en el futuro, ignorando la mera falta de concordancia lógica del acto particular y el acto universal de Kant. Dice Jonas (1995) sobre Kant, “(...) la ética kantiana nos ha servido sólo de ejemplo. Lo que se cuestiona no es su validez en el ámbito que le es propio, sino su suficiencia ante las nuevas dimensiones de la acción humana" (p. 49). De esta manera, Jonas logra introducir su imperativo y su ética orientada hacia el futuro como algo novedoso que viene a resolver problemas antes desconocidos y que no pueden ser solucionados por los modelos éticos clásicos, especialmente por la ética kantiana y sus limitaciones lógicas.

${ }^{4}$ Cf. Kant (2012), p. 74. 


\section{LA DIFERENCIA ENTRE EL 'PODER' Y EL 'PODER QUERER' EN EL ALCANCE DEL} IMPERATIVO CATEGÓRICO.

En la obra Fundamentación para una metafísica de las costumbres Kant tiene por objeto esbozar la base para un principio supremo de la moralidad (Kant, 2012, p. 60.), a decir, el imperativo categórico, el cual es formulado en su forma más universal como "obra sólo según aquella máxima por la cual puedas querer que al mismo tiempo se convierta en ley universal" (Kant, 2012, p. 104). Resumidamente, el imperativo categórico es la condición que deben cumplir las acciones que son guiadas por inclinaciones personales subjetivas (máximas) para que éstas sean acciones morales. ${ }^{5}$ Para Kant, la voluntad o razón práctica enfrenta dos escenarios posibles a la hora de actuar. Por una parte, puede elegir actuar siguiendo, es decir, mandatos provistos por móviles contingentes a posteriori que pueden o no ser válidos universalmente, o, por otro lado, puede actuar obedeciendo las leyes de la razón, las cuales son a priori (universales y necesarias). ${ }^{6}$ Lo que el imperativo categórico estipula es que si se va a actuar siguiendo una máxima, entonces para que esa acción sea moral (o no sea inmoral) se debe poder querer que ese mandato pueda ser universal. Es especialmente importante tener en cuenta que el imperativo categórico estipula un 'poder querer' y no solamente un 'poder'.

Hay dos razones por las cuales uno puede querer que una máxima sea o no una ley universal. La primera es la razón que menciona Jonas y tiene que ver con el carácter lógico de la máxima y la concordancia con su universalización. Kant provee dos ejemplos en el segundo capítulo de la Fundamentación de una metafísica de las costumbres que dejan ver claramente este uso lógico (o estricto) del imperativo categórico. El ejemplo más claro es con respecto a la no devolución de los préstamos. $\mathrm{Si}$ alguien pide prestado y promete devolverlo, sabiendo que no lo va a devolver, entonces él está actuando inmoralmente, porque si se universaliza su máxima (de acuerdo con el imperativo categórico) la máxima entra en contradicción con la ley universal. Esto se debe a que, si todos actuaran bajo la máxima de "no devolver lo prestado", entonces pedir prestado dejaría de tener sentido, pues si todos dejan de devolver lo prestado, entonces ya no hay préstamo. Aquí se puede ver claramente cómo una máxima es inmoral en sentido lógico cuando no se puede universalizar, pues hay ciertos conceptos que al universalizarse dejan de tener sentido. El otro ejemplo que provee Kant con respecto a este uso del imperativo categórico es sobre el suicidio. Kant sostiene que es inmoral actuar en contra de la propia vida, porque si suicidarse se hiciese una ley universal que todos siguieran, entonces ya no habría

\footnotetext{
${ }^{5}$ En el sentido de no inmorales o moralmente buenas.

${ }^{6}$ Sobre los conceptos a priori y a posteriori ver Crítica de la razón pura, 2009, pp. 49-50.
} 
vida, ${ }^{7}$ y el concepto suicidio ya no tendría sentido porque éste requiere del concepto vida. La máxima entra en contradicción con su versión universal, pues si no hay vida entonces no puede haber suicidio.

Ambos ejemplos de este uso del imperativo categórico apelan a la contradicción interna que se genera cuando se niega una parte analítica de un concepto. El concepto pedir prestado contiene en sí mismo analíticamente la devolución, así como el suicidio contienen analíticamente en sí el concepto de vida, y cuando se niega alguna parte del análisis del concepto (en el sentido analítico), entonces el concepto deja de tener sentido.

Sin embargo, cabe aclarar que, para estos casos del uso del imperativo categórico, es decir, en su uso estricto, el concepto 'querer', en 'poder querer', no es necesario. Si el imperativo categórico fuese "obra sólo según aquella máxima por la cual puedas al mismo tiempo convertirla en ley universal" la contradicción de ambos ejemplos seguiría siendo válida, pues los ejemplos tienen que ver con el carácter lógico de los conceptos de la máxima y su universalización, no con un carácter volitivo. Si todos no devuelven los préstamos, entonces el préstamo deja de tener sentido, se quiera o no. Para estos casos el 'querer' estipulado en el imperativo categórico original es innecesario, pues como sugiere Jonas, aquí lo único que importa para evaluar la moralidad de una acción es que no haya contradicción lógica entre una máxima y su universalización. Por ejemplo, si se define analíticamente el concepto triángulo como "una figura cerrada de tres ángulos", y se niega el concepto figura, entonces el concepto triángulo deja de tener sentido, se quiera o no. Es análogo a lo que sucede con el caso del préstamo, pues se puede deducir analíticamente que el concepto préstamo incluye en sí el devolver, y si se niega el concepto de devolución, entonces el concepto préstamo deja de tener sentido. "Obsérvese que aquí la reflexión fundamental de la moral no es ella misma moral, sino lógica; el 'poder querer' o 'no poder querer' expresan autocompatibilidad o autoincompatibilidad lógica, no aprobación o desaprobación moral." (Jonas, 1995, p. 39). Estos ejemplos dejan ver que el imperativo categórico tiene un uso estrictamente lógico cuando se considera en cuanto a un poder, y que hay casos donde de hecho se puede aplicar ese uso lógico al actuar práctico en general. En los dos ejemplos anteriores el 'querer' del 'poder querer' es irrelevante, pues hay una primacía en la restricción lógica que se deja ver en el verbo 'poder'.

Sin embargo, el hecho de que Kant estipule el imperativo categórico utilizando el concepto 'poder querer' y no sólo el verbo 'poder', es porque así el imperativo categórico logra incluir casos de moralidad que van más allá de la mera contradicción lógica. Esto es evidente si se analizan los siguientes dos ejemplos

\footnotetext{
${ }^{7}$ Vida capaz de suicidarse.
} 
que Kant provee cuando termina de formular el imperativo categórico. El tercer ejemplo tiene que ver con un uso del imperativo categórico que no es estrictamente lógico, pues plantea el problema sobre si es inmoral que alguien con afortunadas disposiciones naturales no las cultive y se entregue al goce. Kant concluye que es imposible querer como ley universal las máximas en favor del mero goce pues "todo ser racional quiere que se desarrollen en él todas las capacidades, ya que le son dadas y resultan útiles para toda suerte de posibles propósitos" (Kant, 2012, p. 107). Aquí se puede ver claramente que este ejemplo es de un carácter muy distinto a los dos ya analizados, pues no hay un problema de autocontradicción de conceptos. El talento del hombre con afortunadas disposiciones naturales no deja de ser tal porque todos los hombres talentosos decidan dedicarse al goce. Es decir, aplicar el imperativo categórico a la máxima "me voy a dedicar al goce en vez de cultivar mis facultades naturales" para que se formule como "todos aquellos con talentos naturales deben dedicarse al goce" no hace que el talento natural deje de existir ni fácticamente ni por contradicción lógica. Por lo tanto, es claro que el uso del imperativo categórico va más allá de la mera contradicción lógica, pues Kant mismo provee ejemplos que no tratan solamente con contradicciones lógicas. Este es un caso donde el poder volitivo del imperativo categórico tiene una mucha mayor importancia, es decir, donde el 'querer' del 'poder querer' toma más fuerza. Este es un sentido lato, pues no es tan estricto como el lógico, pero que sirve para incorporar un mayor número de casos morales a la moral del imperativo categórico. Al mismo tiempo el sentido lato permite reforzar el énfasis que Kant otorga a la libertad del individuo, pues cada uno es libre de querer actuar o no actuar de una determinada forma, especialmente cuando no hay una contradicción lógica evidente que guíe el camino. Aquí se puede ver la primera razón de por qué la interpretación que Jonas hace sobre el imperativo categórico Kant es solamente parcial, pues este ejemplo deja en evidencia que el imperativo categórico no es solamente aplicado en el plano lógico.

El cuarto ejemplo que provee Kant (2012) es el más iluminador al momento de mostrar que una interpretación meramente lógica de su imperativo categórico es imparcial. En éste plantea el problema de la beneficencia, y sobre si es necesario o no que se practique.

“¿Que cada cual sea tan dichoso como el cielo quiera o pueda hacerse a sí mismo, que yo no le quitaré nada ni tan siquiera la envidiaré, sólo que no me apetece contribuir en algo a su bienestar o a su auxilio en la indigencia!”. (p. 107).

Kant resuelve que, si esta actitud guiada por máximas que indican no practicar la benevolencia se hiciesen ley universal de la naturaleza, la humanidad podría subsistir perfectamente, pues no es que se busque perjudicar al otro, sino simple- 
mente no beneficiarlo. Es decir, no hay ni un problema lógico, ni aparentemente de cualquier otra índole, en hacer que la no benevolencia fuese una ley universal. Sin embargo, Kant (2012) sostiene que "aun cuando es posible que según aquella máxima pudiera sostenerse una ley universal de la naturaleza, es con todo imposible querer que un principio semejante valga por doquier como una ley natural" (pp. 107-108).

Es aquí donde se puede ver más claramente la distinción entre 'poder' y 'poder querer'. Kant dice explícitamente que una ley universal de no benevolencia es posible, es decir, es lógicamente aceptable porque no genera contradicción; sin embargo, es imposible de querer. En este ejemplo, es claro cómo el peso del imperativo está acentuado en el verbo 'querer' y no el verbo 'poder'. Dice Kant (2012) que no se puede querer que tal máxima sea ley universal porque:

"una voluntad que decidiera eso se contradiría a sí misma, al poder darse algunos casos en que precise amor o compasión por parte de otros y en los que, merced a una ley natural emanada de su propia voluntad, se arrebataría la esperanza de auxilio que desea para sí.” (p. 108).

Aquí hay una contradicción, pero no es una contradicción lógica como en los dos primeros ejemplos, es una contradicción de carácter volitivo, donde la voluntad no puede querer negarse ayuda a sí misma, pues al negar la benevolencia en forma de ley universal se previene que los demás seres racionales, guiados posiblemente por la razón, practiquen la benevolencia entre ellos y hacia uno mismo. Es imposible, según Kant, para la razón querer negarse ayuda a sí misma. "Algunas acciones están constituidas de tal modo que su máxima no puede ser pensada sin contradicción como ley universal de la naturaleza y mucho menos que uno pueda querer que deba volverse tal" (Kant, 2012, p. 108).

Por lo tanto, si tenemos en cuenta este uso lato del imperativo categórico, es decir, el uso que va más allá de la mera contradicción lógica, la estipulación de Jonas sobre que su propuesta es novedosa queda en jaque, porque se puede usar el sentido lato para analizar los casos novedosos de la técnica moderna. Jonas argumenta que el imperativo categórico de Kant es incapaz de lidiar con problemas como la existencia de la humanidad porque solamente puede lidiar con problemas de contradicción lógica entre máximas y leyes universales. Es decir, para Jonas el problema no es solamente que el imperativo categórico sea incapaz de proteger a la vida humana auténtica sino además que el imperativo categórico ni siquiera puede tratar el tema, porque no es un problema lógico. Sin embargo, como se mostró con los ejemplos tres y cuatro que el mismo Kant provee después de enunciar el imperativo categórico, podemos ver que este último no solamente tiene un carácter lógico, sino también uno que tiene que ver con la volición. 
Por lo tanto, la pregunta ahora vendría a ser si se puede querer desde un punto de vista de la ética kantiana (con énfasis en el querer) que una máxima que atente contra la existencia de la humanidad pueda convertirse en ley universal. En primera instancia, desde un punto de vista lógico, Jonas tiene razón, no hay nada en el concepto humanidad que exija permanencia o existencia. Sin embargo, ¿se puede querer, así como se podría querer que no haya benevolencia o que no se desarrollen los talentos naturales, que la humanidad deje de existir? La pregunta no es fácil de responder, pues depende, si se asume que la humanidad es buena (como lo es seguir las máximas a favor de la benevolencia) y si la existencia es buena también, es decir, si la existencia de la humanidad puede ser un deber.

Estas preguntas apuntan hacia la esencia misma del hombre y la existencia. Si la humanidad es buena y la existencia también, entonces ¿por qué no habría de poder quererse que exista, es decir, que se prohíban moralmente las máximas que al hacerse leyes universales atenten contra su existencia? O, dicho de otro modo, si el hombre es bueno y también su existencia, ¿por qué no se obraría a favor de que perdure su existencia?

Queda entonces demostrado que la solución del nuevo imperativo de Jonas no es tan novedosa como él la hace parecer, pues el viejo imperativo no se reduce solamente a un uso estrictamente lógico, con lo cual se puede analizar la problemática jonasiana usando el sentido más lato. ¿Se puede querer obrar de tal forma que ciertas máximas, convertidas en leyes universales, atenten, por ejemplo, contra la existencia de la humanidad o del planeta?

\section{USANDO EL SENTIDO LATO DEL IMPERATIVO CATEGÓRICO PARA RESPONDER LAS} PROBLEMÁTICAS DE LA TÉCNICA MODERNA: ASEGURANDO LA EXISTENCIA DE LA HUMANIDAD Y DEL MUNDO.

El problema que se presenta para responder las problemáticas de la existencia de la humanidad y del mundo en la ética kantiana es cómo se puede asegurar que la existencia de la humanidad (o del mundo) sea algo bueno, es decir, que la existencia de ambos es algo que se debe asegurar a través del deber. Como se vio anteriormente, usando el sentido lógico del imperativo categórico no se puede estipular como un deber que la humanidad o el mundo deban existir, pues no hay contradicción alguna si no existen, ya que la existencia no forma parte analítica del concepto humanidad (o mundo), ${ }^{8}$ por lo cual no hay contradicción si no existen.

\footnotetext{
${ }^{8}$ Mundo en el sentido que lo utiliza Jonas, es decir, como el planeta que habitamos, no en el sentido kantiano de mundo como idea de la razón pura.
} 
Para asegurar ambas existencias desde el punto de vista del imperativo categórico kantiano es necesario explicar qué entiende Kant por existencia, cuál es su prerrequisito y qué es lo bueno en sí. Aclarar estos tres conceptos permite concluir que la existencia es un deber que se puede asegurar utilizando el imperativo categórico.

La existencia para Kant es una categoría o concepto puro del entendimiento. Específicamente, la existencia es una categoría de modalidad que permite darle forma a la materia de lo intuido al permitir efectuar juicios asertóricos del tipo 'S es efectivamente P'. Desde este punto de vista, la existencia para Kant es un predicado y como tal sólo puede aplicarse a fenómenos, es decir, a aquello que es intuido por la sensibilidad, porque como forma pura del entendimiento ésta se aplica a la materia que provee el fenómeno. Esto es importante de tener en cuenta porque cuando Kant habla de existencia está usando el concepto de esta manera, como un posible predicado que es posible porque forma parte de una categoría que tiene como prerrequisito un múltiple que al menos esté ordenado secuencialmente por la intuición pura del tiempo, el cual se obtiene cuando un objeto es intuido y al cual nosotros aplicamos las formas puras de la intuición. Es decir, no se puede afirmar válidamente la existencia de algo que no es intuido. El noúmeno o la cosa en sí, por otro lado, es aquello que no se puede conocer porque no ha sido intuido; sin embargo, cuando se presenta ante un sujeto es intuido y se convierte en fenómeno, es decir, el noúmeno es condición necesaria para que haya fenómeno al cual se le pueda aplicar la categoría de existencia. Por lo tanto, si Kant asegura que algo tiene que existir, él presupone la necesidad de que ese algo pueda manifestarse como fenómeno ante un sujeto que pueda aplicarle la categoría de existencia, lo cual presupone la dimensión nouménica del fenómeno, pues el noúmeno no es más que la cosa no conocida, es decir, a la cual no hemos aplicado forma alguna, pero que, sin embargo, al ser intuida provee la materia a la cual se le aplican las formas a priori. Teniendo claro qué significa existencia en el sentido kantiano cabe entonces analizar qué es lo bueno en Kant y si se puede querer la existencia de la humanidad y del mundo.

Para Kant no es posible pensar nada que pueda ser tenido por bueno sin restricción alguna excepto la buena voluntad. Una buena voluntad es aquella que decide libremente obedecer los mandatos a priori de la razón por sobre el de los móviles contingentes a posteriori. El hombre pertenece al grupo de los seres racionales y en cuanto tal decide libremente seguir o no el mandato de su propia razón, con lo cual obtiene dignidad y pasa a ser persona, estatuto que lo distingue de las cosas. Para Kant, su naturaleza racional además le provee la calidad de fin en sí mismo pues "la naturaleza racional se exceptúa de las demás por fijarse a sí misma como un fin" (2012, p. 127). Es decir, la razón es la característica definitoria del ser 
humano y como tal se define a sí misma como un fin en sí mismo o como aquello que es bueno en sí mismo. Por lo tanto, la razón en cuanto teórica y práctica es el fundamento de lo bueno, pues es lo que posibilita que la voluntad (razón práctica) pueda elegir seguir las leyes universales que la razón (teórica) prescribe. La voluntad es buena o moral cuando decide seguir el mandato necesario de la razón por sobre el mandato de los móviles contingentes que buscan la felicidad.

Para Kant la felicidad del ser humano tiene tanto un carácter necesario como uno contingente: necesario porque todos buscan ser feliz, pero también tiene un carácter a posteriori ya que todos los seres humanos son felices por distintas razones. Esto se deja en evidencia cuando se analiza la forma lógica de los juicios contingentes que utiliza la razón para ser feliz. La persona que busca ser feliz obedece imperativos con forma hipotética asertórica, del tipo 'Si S es efectivo, entonces P'. Esta forma del juicio evidencia que la felicidad no es a priori porque el imperativo está establecido por una condición que es contingente y depende efectivamente de la naturaleza particular de cada uno. Sin embargo, es un hecho que el hombre en cuanto ser racional libre se ve enfrentado ante la opción de seguir los imperativos contingentes que lideran hacia la felicidad porque la felicidad se le muestra como una necesidad, aunque los imperativos contingentes no sean necesariamente morales ${ }^{10}$ o muchas veces sean inmorales. Aquí se puede apreciar la separación entre querer y deber en Kant, pues el hombre quiere ser feliz, pero debe obedecer el mandato de la razón, y cuando elige el deber por sobre el querer entonces es cuando la voluntad actúa más moralmente o es mejor. Cuando la voluntad elige desobedecer el mandato de los móviles que buscan la felicidad en aras de cumplir las prescripciones universales de la razón, entonces es cuando está siendo más moral. Por lo tanto, la voluntad es buena si al verse enfrentada ante la libre elección entre móviles contingentes a posteriori y leyes necesarias a priori, ella decide guiarse por los preceptos a priori.

Finalmente, respondiendo a la problemática de Jonas con respecto a la existencia, ¿se puede querer que el ser humano siga existiendo? O más específicamente, ¿se puede querer que las máximas que guían el comportamiento de la humanidad aseguren la existencia de la humanidad al hacerse leyes universales? Sí se puede querer -y se debe querer- si se considera que lo bueno en sí, desde el punto de vista kantiano, es el producto de una elección libre entre lo a priori y lo a posteriori. Se necesita esta dicotomía compuesta por una parte a priori y una a posteriori para que haya aquello que es bueno, y la parte a posteriori de la decisión libre proviene de móviles contingentes que se nos presentan como fenómenos porque también existimos fenoménicamente. Es decir, si el hombre no existiese en cuanto fenómeno,

10 Sólo son morales si pueden pasar la prueba del imperativo categórico. 
sino solamente existiese en la forma de un sujeto trascendental, éste no se vería afectado por los móviles contingentes a posteriori que lo dirigen hacia la felicidad y que posibilitan que la elección de la voluntad sea buena, pues se necesita tener la posibilidad de elegir entre lo contingente y lo necesario para que al elegir lo necesario el acto sea moral o bueno. Por lo tanto, volviendo al imperativo categórico y su formulación con énfasis en el sentido lato, es un deber asegurar la existencia de la humanidad en cuanto conjunto de seres racionales porque es a sus miembros a los que se les presentan los fenómenos contingentes que permiten la libre elección entre máximas y leyes de la razón, posibilitando la existencia de lo único bueno en sí: la voluntad que elige el mandato de la razón por sobre el de los móviles contingentes, es decir, la buena voluntad. Kant (2012) sostiene:

"Las personas, por lo tanto, no son meros fines subjetivos cuya existencia tiene un valor para nosotros como efecto de nuestra acción, sino que constituyen fines objetivos, es decir, cosas cuya existencia supone un fin en sí mismo y a decir verdad un fin tal en cuyo lugar no puede ser colocado ningún otro fin al servicio del cual debiera quedar aquél simplemente como medio, porque sin ello no encontraríamos en parte alguna nada de ningún valor absoluto (...)” (p. 115).

Aquí se puede apreciar claramente que para Kant la existencia de las personas, en cuanto seres racionales que son fines en sí mismo, supone en sí un fin en sí mismo. Si analizamos la existencia desde el punto de vista del fenómeno, entonces lo que Kant está aseverando es que la existencia en cuanto fenómeno de las personas debe considerarse como un fin en sí mismo, pues sólo en cuanto fenómeno se puede aseverar válidamente que una persona existe y sin ello no encontraríamos en parte alguna nada de ningún valor absoluto. A la ética kantiana no le basta solamente con estipular un sujeto trascendental sin un correlato fenoménico o empírico, pues es gracias a que existe que éste tiene la posibilidad de ser bueno. Si lo bueno es aquello que se debe ${ }^{11}$ entonces la existencia es un deber porque es la condición de posibilidad de lo bueno.

Por lo tanto, sí se puede utilizar el imperativo categórico -en un sentido que Jonas ignora- para asegurar la existencia de la humanidad, pues la voluntad es lo único que puede ser bueno y para serlo necesita pertenecer a los fenómenos. Esto no se limita sólo a la existencia presente de los seres humanos, pues en cuanto éstos existen y siguen existiendo mediante la procreación, el futuro de la humanidad queda asegurado como una prolongación del presente. Si la existencia actual de la humanidad es condición de posibilidad de lo bueno, entonces también lo es en su futuro, pues si la humanidad dejase de existir esto sería algo malo ya que la existencia es condición de posibilidad necesaria para lo bueno y lo bueno es a lo que le corresponde el deber moral.

\footnotetext{
${ }^{11}$ En el sentido de deber moral.
} 
Con respecto al mundo físico, también se puede justificar el deber de procurar su existencia si se considera que la existencia de la humanidad es algo que se quiere porque es bueno y que el mundo es un medio necesario para asegurar dicho fin. "Quien quiere un fin, quiere también (en tanto que la razón ejerce un influjo decisorio sobre sus acciones) el medio indispensable para ellos que se halla en su poder. Esta proposición es analítica en lo que atañe al querer (...)" (Kant, 2012, p. 98). Por lo tanto, usando el imperativo categórico se puede asegurar que la existencia del mundo en cuanto medio es un deber porque es un medio necesario para que la humanidad exista, y sí se puede querer que la humanidad exista pues en ella en cuanto existente reside la posibilidad de todo lo bueno. De esta manera se pueden justificar éticamente todas las cosas necesarias para que exista la humanidad, dejando claro que son necesarias sólo en cuanto son medios para un fin que se quiere, no porque se quieran como cosas en sí pues no son, según la ética kantiana, buenas en sí.

\section{RESPUESTAS ANTE LAS NUEVAS PROBLEMÁTICAS DE LA TÉCNICA MODERNA} DESDE LA PERSPECTIVA KANTIANA: EL PROBLEMA DE LAS TRES PREMISAS TÁCITAS

DE LAS ÉTICAS CLÁSICAS.

Como se dijo al comienzo del ensayo, Jonas establece que hay tres suposiciones tácitas y fijas bajo las cuales todas las éticas clásicas operaban, suposiciones que hoy en día ya no son necesariamente inalterables pues el alcance de la técnica moderna permite modificarlas. Ante estas posibles modificaciones las éticas clásicas, según Jonas, no tienen cómo hacerse cargo de las nuevas problemáticas pues el bien que dirigía el actuar humano, el cual tiene como prerrequisito una condición humana fija, queda indeterminado al verse la condición humana potencialmente afectada por la técnica moderna. Cabe, sin embargo, sugerir respuestas consistentes basadas en el análisis anterior que sí permiten hacerse cargo de los problemas potenciales que plantea Jonas.

Uno de los ejemplos que plantea Jonas con respecto al problema de que la condición humana que deja ser de fija es la posibilidad de que la inmortalidad ya no sea sólo una pretensión, sino que ésta sea una realidad que prometen ciencias como la citología. La prolongación indeterminada de la vida presenta varios problemas potenciales para Jonas desde distintas perspectivas, ya sean sociales, políticas o individuales. Sin embargo, lo que es común a todas es que:

"ese regalo que ya tenemos en perspectiva (la potencial posibilidad de la vida eterna) ha hecho que surjan nuevas preguntas, preguntas que nunca antes fueron planteadas en términos de elección práctica y que ningún principio de ética anterior -que tomaba las constantes humanas como algo evidente- está capacitado para debatir" (Jonas, 1995, pp. 51-52). 
Esto, sin embargo, no parece ser el caso para la ética kantiana. Desde un punto de vista kantiano basado en la Fundamentación de una metafisica de las costumbres se puede argumentar que lo más importante para Kant, en cuanto a lo que tiene que ver con el carácter esencial del ser humano, es que éste es un ser racional con una voluntad libre y que en cuanto tal su voluntad y su razón teórica no siempre coinciden o concuerdan ya que la voluntad es libre para elegir tanto el mandato de la razón como el de los móviles contingentes. Esto es lo que caracteriza al ser humano, pues es en la relación de subordinación entre la voluntad y la razón teórica donde el ser humano encuentra su especial dignidad y el ser un fin en sí mismo. Cuando el ser humano elige voluntariamente seguir las leyes de su razón como si fueran leyes de la naturaleza, es decir necesarias, entonces éste está actuando moralmente mediante una buena voluntad. El sujeto racional es legislador (agente) de las leyes universales que propone su razón y, por el otro lado, es legislado (paciente) cuando elige seguir libremente las leyes que él mismo se propone mediante la voluntad. Para Kant lo único que es moralmente bueno en sí sin restricción es la buena voluntad, es decir, la voluntad que elige libremente seguir el mandato universal de su razón por sobre el mandato de los móviles contingentes.

Por lo tanto, la ética kantiana sí tiene una respuesta a la nueva problemática de la técnica moderna que según Jonas las éticas anteriores no están capacitadas para debatir. Puede ser que algunos aspectos de la condición humana ya no estén tan fijos a causa de la técnica moderna, pero mientras el ser humano siga siendo una voluntad libre que sea capaz de autolegislarse a través de la razón, éste seguirá siendo un humano auténtico que pertenece al reino de los fines y como tal, cualquier cambio de la técnica moderna que no afecte esta condición no afectará su esencia ni lo privará de su especial dignidad o bondad. Esto provee una respuesta a la problemática de Jonas, una respuesta para la cual supuestamente esta ética clásica no estaba capacitada para debatir.

Habiendo determinado cuál es el rasgo de la condición humana que Kant debe proteger del potencial cambio a manos la técnica moderna, cabe ahora hacerse cargo de determinar con claridad cuál es el bien que se debe perseguir teniendo en cuenta dicha condición. Desde la perspectiva kantiana se puede justificar que se debe resguardar la existencia de la humanidad y también promover la concordancia entre razón y voluntad.

Por lo tanto, se tienen que proteger y asegurar todos los medios necesarios para que el ser humano exista, tanto como humanidad, pero también en cuanto individuos que son fines en sí. A esto se puede sumar que se debe promover la concordancia entre razón y voluntad, sea mediante educación, leyes, etc., para que la humanidad sea mejor. ${ }^{12}$ Por último, y respondiendo a la última problemática de

${ }^{12}$ Cf. Kant (2010), pp. 641-645. 
Jonas con respecto al alcance de la acción humana y su responsabilidad, se deduce de todo lo anterior que la acción humana debe hacerse responsable de cuidar todos los medios necesarios para la existencia de la humanidad y de promover que la voluntad concuerde con la razón. Esto vale tanto para el presente inmediato como para el futuro, pues la existencia de la humanidad en cuanto seres racionales siempre es necesaria para que exista lo único bueno en sí.

\section{Conclusión}

El ensayo busca exponer cómo se pueden enfrentar las problemáticas propias de la técnica moderna que Jonas plantea desde una perspectiva kantiana. Para esto se busca 1) responder a la crítica que Jonas hace sobre el problema del alcance del imperativo categórico y cómo éste es incapaz de asegurar la existencia de la humanidad y 2) cómo la ética kantiana permite hacerse cargo de los problemas éticos contemporáneos, aunque las tres premisas tácitas, fundamentales e inalterables que suponen las éticas clásicas -según Jonas- ya no lo sean.

Para 1) el ensayo muestra cómo la interpretación crítica que hace Jonas sobre Kant, que a su vez utiliza para presentar su ética como una ética con un alcance novedoso y sin precedente en las éticas clásicas, es parcial porque no hace un análisis completo que sí permite ofrecer respuestas a las preguntas que él mismo plantea. Para mostrar esto se demuestra que el imperativo categórico no tiene solamente un uso lógico formal, sino que además tiene un uso que se centra en el «querer» del «poder querer» del imperativo categórico, lo cual posibilita el análisis de casos morales que van más allá de la mera contradicción lógica. Después se demuestra que la problemática sobre la existencia de la humanidad como un deber, que Jonas utiliza como ejemplo para mostrar cómo la ética kantiana es insuficiente pues no puede asegurarla, es de hecho parte fundamental de la ética kantiana ya que es la existencia la que posibilita la elección entre mandatos a priori y a posteriori, lo cual es fundamento de lo bueno.

Con respecto a 2) -y basándose en 1)- se muestra que el aspecto de la condición humana más importante para Kant es su capacidad de elegir libremente entre los mandatos de la razón y los mandatos de los móviles contingentes. Con esto claro se puede determinar que el bien a seguir es asegurar y promover los medios necesarios para que la voluntad exista y concuerde en mayor medida con la razón.

Muchas de las respuestas que se obtienen de la ética kantiana van en la misma línea que las soluciones que Jonas plantea, pues se pueden deducir consecuencias prácticas similares a las que busca el imperativo de Jonas (1995): "incluye en tu elección presente, como objeto también de tu querer, la futura 
integridad del hombre" (p. 40). En el caso tanto de Kant como de Jonas, la integridad del hombre incluye la necesidad de su existencia. ${ }^{13}$

\section{BIBLIOGRAFÍA}

Andren, M. (2012): “An Uncomfortable Responsibility: Ethics and Nuclear Waste”, The European Legacy, 17, pp. 71-82.

Jonas, H. (1995): El principio de responsabilidad. Barcelona, España: Herder.

Kant, I. (2009): Crítica de la razón pura. México D.F.: Fondo de Cultura Económica.

Kant, I. (2010): “En torno al tópico: 'Eso vale para la teoría, pero no sirve de nada en la práctica'". Kant, vol. II. Madrid: Gredos.

Kant, I. (2012): Fundamentación para una metafísica de las costumbres. Madrid: Alianza Editorial.

Levy, L. (1997): "Philosophical ethics meets technology: a difficult state of affairs". Global Bioethics, 10, pp. 35-54.

Pommier, E. (2012): “La responsabilité en discussion: Apel/Jonas”, Revue Philosophique de la France et de l'Étranger, 4, pp. 495-514.

Pommier, E. (2015): "Life and Anthropology: A Discussion between Kantian Criticism and Jonasian Ontology”, Giornale Critico di Storia delle Idee, 45, pp. 121-134.

\footnotetext{
${ }^{13}$ Agradecimientos a Eric Pommier y Ximena Rubio.
} 